\title{
The Effect of Family-Centered Empowerment Model on the Quality of Life of Patients with Leukemia
}

\author{
Mohsen Davarpanah, ${ }^{1}$ Sedigheh Fayazi, ${ }^{2,}$ Abdolali Shariati, ${ }^{2}$ and Seyyed Davoud Mirhosseini ${ }^{3}$ \\ ${ }^{1}$ Thalassemia and Hemoglobinopathy Research Center, Health Research Institute, Ahvaz Jundishapur University of Medical Sciences, Ahvaz, IR Iran \\ ${ }^{2}$ Nursing Care Research Center in Chronic Diseases, Ahvaz Jundishapur University of Medical Sciences, Ahvaz, IR Iran \\ ${ }^{3}$ Department of Pharmacy School, Shahid Beheshti University of Medical Science Tehran, IR Iran \\ "Corresponding author: Sedigheh Fayazi, Nursing Care Research Center in Chronic Diseases, Ahvaz Jundishapur University of Medical Sciences, Ahvaz, IR Iran. E-mail: \\ sadighe_fa@yahoo.com
}

Received 2016 February 03; Revised 2016 May 17; Accepted 2016 May 25.

\begin{abstract}
Background: Leukemia is a common cancer among adults with growing prevalence in Iran. This disease affects different aspects of the patient, especially their quality of life. One of the methods to promote hygiene and health and, consequently, quality of life is to empower the family of the patient.

Objectives: The effect of family-based empowerment on quality of life in patients with leukemia was studied in this research. Methods: This study was a clinical trial conducted on 46 adult patients with leukemia together with 46 of their family members in 2015. Eligible patients were selected by the available method and randomly placed in two groups of test and control. Tools for gathering data included a demographic questionnaire about the patient and their family member and a specified questionnaire about the quality of life of patients with cancer. Family-based empowerment intervention was held for research samples in the test group based on its quadruple steps (perceived threat, self-efficiency promotion, increase of self-esteem through educational participation, and assessment) in six 90-minute sessions and a second test was conducted a month and half after the intervention. Data were analyzed using the SPSS 20 statistical software.

Results: Results of chi-square test reflected that both groups of test and control were similar in terms of demographic information $(\mathrm{P}>0.5)$. Moreover, statistical independent T-test did not show a significant difference in aspects of quality of life in test and control groups before the intervention $(\mathrm{P}=0.98)$ while this test showed a significant difference in both groups after the intervention ( $\mathrm{P}$ $=0.00)$, except for the spiritual aspect $(\mathrm{p}=0.2)$. Paired T-test indicated a significant increase in aspects of quality of life in the test group after the intervention $(\mathrm{p}=0.00)$ while this test reflected a reverse significant difference in general aspect of quality of life in the control group $(\mathrm{P}=0.006)$.

Conclusions: In general, results of this research showed that implementing family-based empowerment pattern has been effective for increasing quality of life in patients with leukemia.
\end{abstract}

Keywords: Leukemia, Family-Based Empowerment Pattern, Quality of Life

\section{Background}

Leukemia is known as one of the nine prevalent cancers in males and one of ten prevalent cancers in females all over the world and is a general cancer among adults in US with more than 40000 new affected cases estimated in 2012 (1). Moreover, its prevalence is growing in Iran so that it had the ninth rank among ten prevalent cancers in 1996 but rose to the fourth rank in 2008. Out of 100000 new cases of registered cancers in Iran, 3.8 of them were leukemia (2). Talaiezadeh and colleagues' study showed that $10 \%$ of all cancers in Khuzatan province were leukemia (3).

Cancer disrupts job, social-economic status and family life of individuals and ruins the patient's life. It affects different aspects of patient's quality of life including spiritual, mental, social and economic status and his/her sexual performance. During the recent years, quality of life of patients with cancer has been the main criteria when considering respond to treatment (4). Therefore, the aim of blood malignancy treatment is to increase patients' longevity and, to some extent, improve his/her abilities to keep living with an appropriate level of quality of life (5).

Quality of life means individuals' perception of their status in life based on cultural context and value system, which relates to objects, expectations and standards of individuals (6). During a study, quality of life of patients with different blood malignancies were compared, and it was reported that patients with leukemia had a low quality of life (7). In addition, a study by Andrad on patients with leukemia, who were under chemotherapy in Brazil in 2013, reflected that mean quality of life was low in social, cognitive and psychological function aspects (8).

In process of caring for a patient, his/her family re- 
quires clear understanding of the disease and such approach promotes health and family welfare and increases patient's quality of life (9). Bapat (2008) and Aklilvand's study on chronic patients showed that family support was an important factor in accepting the disease and promoting quality of life $(10,11)$. Therefore, implementing an empowerment program with the aim of increasing knowledge and awareness and self-efficiency that results in behavioral self-control and makes preventive behaviors would be necessary in order to promote hygiene and improve quality of life (12).

The study by Nassehi et al. (2014) with an aim to investigate the effect of family-based empowerment program on patients with asthma indicated that total score and quality of life's aspects were significantly different after the intervention when compared to the pretest (13); moreover, the study of Ghasemi et al. (2014) showed that an empowerment program made an improvement in the process of patients' social support and quality of life (14). The study of Clary et al. (2009) on hemodialysis patents showed that patients' motivation increased after implementing an empowerment program and, also, a considerable increase was observed in self-efficiency, self-esteem and quality of life of patients (15).

Health caregivers have an important role in empowering family members to decrease tension (16); meanwhile, nurses are one of the most appropriate members of the health team for training clients and their family due to their vocational and professional responsibility and ability to undertake different roles in health service systems (17). The aim of nursing intervention in family-based care is to promote capabilities of family members in definite realms in order to overcome barriers in health and hygiene fields $(18,19)$.

Regarding emphasis on family cooperation for patient care, this important issue is rarely implemented and programmed as an official process in teaching clients. The effectiveness of family-based empowerment programs on chronic patients has been confirmed yet it has not been examined on patients with leukemia so far. In addition, regarding the increase in the prevalence of leukemia and the chronic nature of this disease, which is problematic for families and has serious side effects, empowering a member of the family can affect family's empowerment as a whole, in order to reach health goals. Moreover, it is expected for the application of this program to result in development of nurses and family's knowledge and promote patients' quality of life.

\section{Objectives}

The present research was conducted with the aim of determining the effect of family-based empowerment program on quality of life of adult patients with leukemia at Shafa hospital of Ahvaz.

\section{Methods}

The present study was a clinical trial (registration code IRCT2015021621100N1R1) conducted on two groups of test and control, based on pre- and post-intervention tests. The intervention consisted of implementing family-based empowerment program for the test group. Based on a similar study (20), the volume of the sample in each group was estimated as 14 patients and 14 family members using Pupak formulation and with confidence level of 95\% and test power of $95 \%$. However, volume of sample increased to 23 patients and 23 caregivers in each group in order to consider possibility of sample loss, increase accuracy of the study and use Fabio Rodrigues Kerbauy' study (21). Sampling was conducted through the available method during fall 2014. Samples were selected from patients hospitalized at the adults hematology ward or patients referred to outpatient chemotherapy ward of Shafa hospital, affiliated to Ahvaz Medical Science University, while an active member of the patient's family was also recruited (a family member who followed the patients in the treatment process in order to achieve an improvement and prompt quality of life and had power of decision and capability of caring for the patient and recognizing his/her status). Patients and families were randomly divided to two groups of control (46 individuals consisting of 23 patients and 23 family members) and test (46 individuals consisting of 23 patients and 23 family members). The criteria for entering in the study included: age of over 18 years, mental ability to take part in the test, the main care giver's acquaintance with Persian language and ability to write and read, not taking part in similar educational classes and not having history of diseases such as psychopathy, cognitive disorder and other neurological disorder. Criteria for exclusion from the study included: having no interest to continue cooperation by the patient or main caregiver, having problems such as bleeding and severe infection and other problems making the patient unable to continue or lead to his/her hospitalization at the Intensive Care Unit (ICU) and missing an educational session. In this study, three patients were omitted from the study due to death, two patients due to recrudescence of disease and three patients due to having no interest in taking part in the research; the study was finally conducted with 20 patients in the test group and 18 patients in the control group. 
Research tool in this study included a check-list of need assessment for the patient and main caregiver, two demographic information questionnaires of patient and family and quality of Life-cancer survivor questionnaire (QoL-CS) with 41 questions. The last questionnaire examined four aspects of quality of life, including physical (8 questions), mental (18 questions), social (8 questions) and spiritual (7 questions). In this questionnaire, answers were computed based on Likert scale from zero to ten; zero reflected the worst quality of life while ten reflected the best quality of life and the total score of the questionnaire was between 0 and 410 .

The demographic information questionnaire consisted of age, gender, level of education, employment status, marital status, family member's relationship with the patient, duration of disease, lifestyle, economic status, kind of leukemia, and duration of the disease.

The questionnaire used for this research was studied by ten masters of psychology and nursing students to examine its content validity and their suggestions and opinions were applied. Moreover, the re-test method was used for ten similar patients in order to determine the reliability of the quality of life tool and reliability coefficient of $\mathrm{r}=$ 0.87 was computed using Cronbach's alpha coefficient.

After receiving necessary approvals, explanations were provided for the patient and their active family member and sampling was then conducted on eligible patients at this center after obtaining their satisfaction. This study was conducted in three phases: at first, check list of need assessment was distributed among samples and facilities, and limitation and needs of patients and caregivers for empowerment were recognized after analyzing first phase's data (before intervention) and the empowering program was designed and implemented correspondingly. In the second phase (intervention), samples were divided to two groups by the simple random method. The control group only received common care of wards yet in the test group, patients and their active family member took part in empowerment pattern-based education by a researcher and one of the employed nurses and by cooperation of a nutritionist of that treatment center. Samples of the test group were divided to four groups and family-based empowerment program was implemented for each group in six 90minute sessions, twice a week. Educational sessions were implemented in the form of lectures, and questions and answers.

Administrative phases of the program consisted of four steps as follows: perceived threat, self-efficiency promotion, and increase of self-esteem through educational participation and assessment. In the first phase (perceived threat), four educational sessions were held within two weeks in order to make patients and family members sen- sitive and increase their level of information. In the second phase (self-efficiency promotion), method of problem solving and questions and answers were concerned with selfefficiency promotion; thus, at first, patients stated their problems and the researcher gave an explanation about the problem and then the patient and their family member were asked to give an explanation for the discussed issue. This gave them an opportunity to practice and repeat and, to some extent, they were capable of doing it without the presence of the researcher. In the third phase (educational participation), the patients were asked to study pamphlets at home after each session, which was done during the first and second phases continuously, and note their questions on cards prepared by the researcher in advance and bring it to the next session to be examined. The forth phase (assessment) was conducted in two steps: process assessment that was conducted during the intervention and before the start of each session and by oral questions related to issues taught in each session. Final assessment or post-test (third phase) was conducted a month and half after the intervention for both groups. Finally, researchers provided the control group with educational materials as an educational pamphlet in order to observe moral issues. Finally, the gathered information was analyzed using the SPSS software and descriptive (mean, standard deviation and tables of frequency distribution) and analytical (chi-square, paired and independent t-test) statistics.

\section{Results}

No statistical difference was observed in between demographic variable of patients and their family member in the two groups of test and control using chi square statistical test and paired t-test $(\mathrm{P}>0.05)$ (Tables 1 and 2). Comparing mean values for different aspects of quality of life of the patients did not show a significant difference between the two groups of test and control after the intervention and both groups were similar. However, comparing mean values of quality of life showed a significant difference in the two groups of test and control after the intervention (except for the spiritual aspect). Moreover, comparing mean and standard deviation values of quality of life in patients with cancer showed a significant increase with statistical paired t-test before and after the intervention in the test group and this significant increase occurred for all aspects of test group's quality of life. However, a significant difference was observed in all aspects of control group' quality of life (except for spiritual aspect) yet it had a decreasing trend (Tables 3 and 4). 
Table 1. Demographic Information of Patients of the Two Study Groups

\begin{tabular}{|c|c|c|c|}
\hline Variables & Control group & Test group & Meaningfulness Level \\
\hline Average age & 42.91 & 39.25 & 0.54 \\
\hline Gender & & & 0.78 \\
\hline Male & $10(45.5 \%)$ & $12(54.5 \%)$ & \\
\hline Female & $8(50 \%)$ & $8(50 \%)$ & \\
\hline Education & & & 0.19 \\
\hline Primary school & $5(27.8 \%)$ & $4(20 \%)$ & \\
\hline Guidance school & $6(33.3 \%)$ & $6(30 \%)$ & \\
\hline High school & $4(22.2 \%)$ & $6(30 \%)$ & \\
\hline University & $3(16.7 \%)$ & $4(20 \%)$ & \\
\hline Marital status & & & 0.19 \\
\hline Single & $2(11.1 \%)$ & $7(35 \%)$ & \\
\hline Married & $14(77.8 \%)$ & $13(65 \%)$ & \\
\hline Others (Deceased) & $2(11.2 \%)$ & $0(0.0 \%)$ & \\
\hline Life style & & & 0.5 \\
\hline With family & $18(100 \%)$ & $19(95 \%)$ & \\
\hline With relatives & $0(0.0)$ & $1(5 \%)$ & \\
\hline Job status & & & 0.34 \\
\hline Unemployed & $9(50 \%)$ & $10(50 \%)$ & \\
\hline Housewife & $3(16.7 \%)$ & $5(25 \%)$ & \\
\hline Employee & $6(33.3 \%)$ & $5(25 \%)$ & \\
\hline Economic situation & & & 0.70 \\
\hline Unfavorable & $7(38.9 \%)$ & $6(30 \%)$ & \\
\hline Intermediate & $9(50 \%)$ & $10(50 \%)$ & \\
\hline Favorable & $2(11.1 \%)$ & $4(20 \%)$ & \\
\hline Cancer type & & & 0.88 \\
\hline ALL & $2(11.1 \%)$ & $3(15 \%)$ & \\
\hline CLL & $3(16.7 \%)$ & $5(25 \%)$ & \\
\hline AML & $11(61.1 \%)$ & $10(50 \%)$ & \\
\hline CML & $2(11.1 \%)$ & $2(10 \%)$ & \\
\hline Disease duration, mo & 23.3 & 21.78 & 0.46 \\
\hline
\end{tabular}

\section{Discussion}

Results of this study showed that there was no significant difference between mean values of quality of life items of the two groups of patients with leukemia before the intervention; yet, the results showed an improvement in test group' quality of life compared with the control group after the intervention while the control group's quality of life had decreased.

Leukemia has a negative effect on patients' quality of life. Santos et al. indicated that patients with leukemia, like other patients with hematologic malignancy, have low quality of life (7). Results of the studies of Andrade and Nabaee' (2013) on patients with leukemia reflected that they had low quality of life $(8,22)$.

In the present study, a significant decrease was observed in control groups' quality of life (177.30 vs. 166.38), which could be due to receiving frequent sessions of chemotherapy, and the progressive and destructive nature of the disease. On the other hand, the decrease in the control group's quality of life can be attributed to inefficiency and non-effectiveness of routine care. Based on the study of Golchin et al., quality of life in the control group with blood cancer decreased, which could be due to the progressive nature of the disease (23). Another study by Stephens et al. on patients with chronic leukemia showed that decrease of quality of life in these patients was due to longrun treatment and short-run chemotherapy and side effects of treatments (24). These studies conformed to the results of the present study.

Results of the present study showed that applying family-based empowerment program could improve quality of life of patients with leukemia. As it was observed, a significant increase occurred in the case group's quality of life (176.13 vs. 218.35). Based on another study on patients, a significant difference was observed before and after the in- 
Table 2. Demographic Information of the Family Members of the Case and Control Group

\begin{tabular}{|cccc|}
\hline Variables & Control Group & Test Group & $\begin{array}{c}\text { Meaningfulness } \\
\text { Level }\end{array}$ \\
\hline $\begin{array}{c}\text { Average age } \\
\text { Gender }\end{array}$ & 31.91 & 29.95 & 0.45 \\
\hline Male & $11(40.7 \%)$ & $16(59.3 \%)$ & 0.2 \\
\hline Female & $7(63.6 \%)$ & $4(36.4 \%)$ & 0.8 \\
\hline Education & $5(27.8 \%)$ & $4(20 \%)$ & \\
\hline $\begin{array}{c}\text { Primary } \\
\text { school }\end{array}$ & $6(33.3 \%)$ & $6(30 \%)$ & \\
\hline $\begin{array}{l}\text { Guidance } \\
\text { school }\end{array}$ & $4(22.2 \%)$ & $6(30 \%)$ & \\
\hline $\begin{array}{l}\text { High } \\
\text { school }\end{array}$ & $3(16.7 \%)$ & $4(20 \%)$ & \\
\hline $\begin{array}{l}\text { University } \\
\text { Marital status }\end{array}$ & $6(33.3 \%)$ & $9(45 \%)$ & \\
\hline Single & $12(66.7 \%)$ & $11(55 \%)$ & \\
\hline Married & & $4(20 \%)$ & \\
\hline Job status & $6(33.3 \%)$ & $4(20 \%)$ & \\
\hline $\begin{array}{l}\text { Unem- } \\
\text { ployed }\end{array}$ & $3(16.7 \%)$ & $12(60 \%)$ & \\
\hline $\begin{array}{l}\text { Housewife } \\
\text { Employee }\end{array}$ & $9.54)$ & \\
\hline
\end{tabular}

tervention in the case group indicating an improvement in case group's quality of life. Lee and Chun (2007) wrote that an empowerment intervention could be effective in improving quality of life of people with chronic disease (25). Moreover, results of this study were consistent with the results of Golchin (23), Sadat (26) and Lorenzo's studies (27). Therefore, applying the above-mentioned method for nurses is considered a new outlook in issue of training patients and family. More detailed study of quality of life's aspects reflected that quality of life of patients in the case group had better mean values in physical, mental and social aspects after the intervention compared with the control group and, consequently, patients experienced less problems compared with the control group. Lorenzo's study on patients with cancer indicated that using group training by the method of lectures and written materials and videos increased all aspects of quality of life in the test group compared with the control group (27). These results were consistent with the findings of Iconomou et al. (28). In the present study, no significant difference was observed in the spiritual aspect of the test group compared with the control group's mean value $(P=0.2)$, which can be due to different conditions of people in the two groups of test and control in terms of spirituality, low reliability of spiritual aspect of this tool for different cultures or high religious beliefs of Iranian people. As the spiritual aspect was developed as a separate and broad item, more studies and wider use of this tool is necessary.
Other results of this study reflected that the spiritual aspect of the control group increased in contrary to other aspects (28.4 vs. 30.00) indicating an importance of spirituality at the time of death and disease. Koeing (2004) suggested that religion and spirituality make positive viewpoints towards the world and are human's haven at the time of life crises and make firm bases against problems, therefore, religious beliefs become important at the time of disease (29). Therefore, this aspect of quality of life must receive more attention in implementing family-based interventions. Moreover, it seems necessary to place emphasis on spirituality in making hope and increasing quality of life in patients with cancer. Results of this research reflected that implementing an empowerment program improved quality of life of patients with leukemia in the test group while control group's quality of life decreased significantly. Williams suggested that patients, who are capable of choosing treatment and preventing side effects of chemotherapy, boost their self-esteem and improve their health in physical and mental realms and their improved capability in caring results in a decrease of stress and finally promotion of quality of life (30).

\subsection{Conclusion}

Based on the results, paying attention to promotion of quality of life in patients with leukemia requires more attention from the ministry of health and treatment considering more serious and extensive treatment programs at hospitals.

Implementing family-based empowerment programs help individuals and their families recognize their deficiencies and feel enough power in order to change their situation and this feeling of ability is achieved through obtaining information, receiving support and promoting life skills. Regarding family-based empowerment program conducted on patients with leukemia and their family members in this study and also the positive results gained, it is recommended for this program to be implemented at a more extensive level with better facilities for patients and their family members as well as other patients with cancer.

\section{Acknowledgments}

The present study extracted from a masters thesis by Mohsen Davarpanah with ethic code of 1393,166, approved by the research center of Thalassemia and Hemoglobinopathies of Shafa hospital, affiliated with Ahvaz Jundishapur University of Medical Science, during year 2014. The masters student, chairmen and personnel of Shafa hospital, and all patients and their families are honored for their cooperation. 
Table 3. Average Difference of Life Quality Aspects Before and After the Intervention in the Control and Test Group ${ }^{\mathrm{a}}$

\begin{tabular}{|c|c|c|c|c|c|c|}
\hline \multirow[t]{2}{*}{ Groups } & \multicolumn{3}{|c|}{ Test $^{\mathbf{b}}$} & \multicolumn{3}{|c|}{ Control $^{\mathrm{C}}$} \\
\hline & Before Intervention & After Intervention & paired $t$ & Before Intervention & After Intervention & paired $t$ \\
\hline Aspect & Mean \pm SD & Mean \pm SD & & Mean \pm SD & Mean \pm SD & \\
\hline Physical & $36.695 \pm .29$ & $47.95 \pm 10.6$ & $\mathrm{P}=0.00$ & $35.73 \pm 5.82$ & $11.18 \pm 31.55$ & $P=0.03$ \\
\hline Psychological & $76.34 \pm 14.49$ & $91.00 \pm 22.25$ & $\mathrm{P}=0.00$ & $72.91 \pm 12.26$ & $67.94 \pm 9.3$ & $P=0.001$ \\
\hline Social & $38.78 \pm 6.63$ & $46.35 \pm 9.52$ & $\mathrm{P}=0.02$ & $40.96 \pm 4.65$ & $36.68 \pm 6.79$ & $P=0.003$ \\
\hline Spiritual & $28.43 \pm 5.29$ & $33.05 \pm 8.14$ & $P=0.03$ & $28.04 \pm 6.11$ & $30.00 \pm 8.8$ & $P=0.31$ \\
\hline Quality of life & $176.13 \pm 28.13$ & $218.35 \pm 34.5$ & $P=0.00$ & $177.3 \pm 21.25$ & $166.38 \pm 29.14$ & $P=0.006$ \\
\hline
\end{tabular}

${ }^{\mathrm{a}}$ Data are given as mean \pm Standard Deviation (SD).

${ }^{\mathrm{b}}$ Test, group that practiced family-based empowerment pattern.

${ }^{c}$ Control, group for which no intervention was done.

Table 4. Average Difference of Life Quality Aspects Before and After the Intervention Between the Control and Test Group

\begin{tabular}{|c|c|c|c|c|c|c|}
\hline \multirow{2}{*}{$\begin{array}{l}\text { Groups } \\
\text { Aspect }\end{array}$} & \multicolumn{3}{|c|}{ Before Intervention } & \multicolumn{3}{|c|}{ After Intervention } \\
\hline & $\begin{array}{c}\text { Test } \\
\text { Mean } \pm \text { SD }\end{array}$ & $\begin{array}{c}\text { Control } \\
\text { Mean } \pm \text { SD }\end{array}$ & Independent t-test & $\begin{array}{c}\text { Test } \\
\text { Mean } \pm \text { SD }\end{array}$ & $\begin{array}{c}\text { Control } \\
\text { Mean } \pm \text { SD }\end{array}$ & Independent t-test \\
\hline Physical & $36.69 \pm 5.29$ & $35.73 \pm 5.82$ & $\mathrm{P}=0.56$ & $47.95 \pm 10.6$ & $31.55 \pm 11.18$ & $\mathrm{P}=0.00$ \\
\hline Psychological & $76.34 \pm 14.49$ & $72.91 \pm 12.26$ & $P=0.04$ & $91.00 \pm 22.25$ & $67.94 \pm 9.30$ & $P=0.00$ \\
\hline Social & $38.78 \pm 6.63$ & $40.69 \pm 4.65$ & $\mathrm{P}=0.04$ & $46.35 \pm 9.52$ & $36.88 \pm 6.79$ & $P=0.00$ \\
\hline Spiritual & $28.43 \pm 5.29$ & $28.04 \pm 6.11$ & $P=0.081$ & $33.05 \pm 8.14$ & $30.00 \pm 8.8$ & $P=0.02$ \\
\hline Quality of life & $176.13 \pm 28.16$ & $177.30 \pm 21.25$ & $\mathrm{P}=0.98$ & $218.35 \pm 34.50$ & $166.38 \pm 29.14$ & $\mathrm{P}=0.00$ \\
\hline
\end{tabular}

\section{Footnote}

Authors' Contribution: Study concept and design, acquisition of data, analysis and interpretation of data, and drafting of the manuscript, Sedigheh Fayazi; Critical revision of the manuscript for important intellectual content, and statistical analysis, Abdolali Shariati; Administrative, technical and material support, and study supervision, Seyyed Davoud Mirhosseini.

\section{References}

1. SEER . Surveillance Epidemiology and End Results Program US: The Surveillance, Epidemiology, and End Results; 2012. Available from: http://seer.cancer.gov.

2. Rajabli N, Naeimi-Tabeie M, Jahangirrad A, Sedaghat SM, Semnani S, Roshandel G. Epidemiology of leukemia and multiple myeloma in Golestan, Iran. Asian Pac J Cancer Prev. 2013;14(4):2333-6. [PubMed: 23725136].

3. Talaiezadeh A, Tabesh H, Sattari A, Ebrahimi S. Cancer incidence in southwest of iran: first report from khuzestan population-based cancer registry, 2002-2009. Asian Pac J Cancer Prev. 2013;14(12):7517-22. [PubMed: 24460327].

4. Montgomery C, Pocock M, Titley K, Lloyd K. Individual quality of life in patients with leukaemia and lymphoma. Psychooncology. 2002;11(3):239-43. doi: 10.1002/pon.557. [PubMed:12112484].

5. Pamuk GE, Harmandar F, Ermantas N, Harmandar O, Turgut B, Demir $\mathrm{M}$, et al. EORTC QLQ-C30 assessment in Turkish patients with hematological malignancies: association with anxiety and depression. Ann Hematol. 2008;87(4):305-10. doi: 10.1007/s00277-008-0445-4. [PubMed: 18219486].
6. Guyatt GH, Feeny DH, Patrick DL. Measuring health-related quality of life. Ann Intern Med. 1993;118(8):622-9. [PubMed: 8452328].

7. Santos FR, Kozasa EH, Chauffaille Mde L, Colleoni GW, Leite JR. Psychosocial adaptation and quality of life among Brazilian patients with different hematological malignancies. J Psychosom Res 2006;60(5):505-11. doi: 10.1016/j.jpsychores.2005.08.017. [PubMed: 16650591].

8. Andrade V, Sawada NO, Barichello E. Quality of life in hematologic oncology patients undergoing chemotherapy [in Portuguese]. Rev Esc Enferm USP. 2013;47(2):355-61. [PubMed: 23743901].

9. Bland R, Darlington Y.The nature and sources of hope: perspectives of family caregivers of people with serious mental illness. Perspect Psychiatr Care. 2002;38(2):61-8. [PubMed:12132632].

10. Bapat U, Nayak SG, Kedleya PG. Demographics and social factors associated with acceptance of treatment in patients with chronic kidney disease. Saudi J Kidney Dis Transpl. 2008;19(1):132-6. [PubMed: 18087143].

11. Ekelund ML, Andersson SI. "I need to lead my own life in any case"a study of patients in dialysis with or without a partner. Patient Educ Couns. 2010;81(1):30-6. doi: 10.1016/j.pec.2009.10.025. [PubMed: 19962846].

12. Alhani F. .Evaluating of family centered empowerment model on preventing iron deficiency anemia, PhD Dissertation [in Persian]. Tarbiat Modares Univ. 2003.

13. Nassehi A, Abbaszadeh A, Borhani F, Jafari M. Effect of two educational models based on compliance and empowerment on the quality of life of patients with asthma [in Persian]. J Nurs Educ. 2013;2(1):1-7.

14. Ghasemi A, Rahimi Foroshani A, Kheibar N, Latifi M, Khanjani N, Eshagh Afkari M, et al. Effects of family-centered empowerment model based education program on quality of life in methamphetamine users and their families. Iran Red Crescent Med J. 2014;16(3):13375. doi 10.5812/ircmj.13375. [PubMed: 24829765]. 
15. Mc Carley P. Patient empowerment and motivational interviewing: engaging patients to self-manage their own care. Nephrol nurs $j$. 2009;36(4):410-2.

16. Asahara K, Omori J, Kobayashi M, Hirano Y, Suzuki Y, Arakida M, et al. A framework for assessing essential public health nursing skills and achievement levels required for students graduating from schools that provide education for obtaining a license as a public health nurse in Japan [ in Japanese ]. Nihon Koshu Eisei Zasshi. 2010;57(3):18494. [PubMed: 20491292].

17. Hasanpour Dehkordi A, Delaram M, Safdari F, Salehi Tali SH, Hasheminia A, Kasiri K. The effects offamily-centeredempowerment modelon the quality of life dialyzed patient [in Persian]. Shahrekord Univ Med Sci J. 2008;2:52-8.

18. Aaltonen P, Richards EL, Webster K, Davis L. Use of the public health nursing bag in the academic setting. Public Health Nurs 2009;26(1):88-94. doi: 10.1111/j.1525-1446.2008.00757.x. [PubMed: 19154196].

19. Masoodi R., Soleimani M. A. , Hasheminia A. M., Qorbani M. The ef fect of family-centered empowerment model on the quality of life in elderly people. Iranin J sci Ghazvin univ med sci. 2010;4(1):64-58.

20. Zygmunt A, Olfson M, Boyer CA, Mechanic D. Interventions to improve medication adherence in schizophrenia. Am J Psychiatry. 2002;159(10):1653-64. doi: 10.1176/appi.ajp.159.10.1653. [PubMed: 12359668].

21. Kerbauy FR, Morelli LR, de Andrade CT, Lisboa LF, Cendoroglo Neto M, Hamerschlak N. Predicting mortality and cost of hematopoietic stemcell transplantation. Einstein (Sao Paulo). 2012;10(1):82-5. [PubMed: 23045832].

22. Nabaei B, Keiltash A, Montazeri A. The comparison of quality of life in patients with leukemia and Lymphoma with Tehran population.
TUMJ. 2005;5:399-404.

23. olchin M, Shabanloei R, Asvadi I, Eivazi ZJ, Nikanfar A, Dolatkhah R. Effects of Self Care Program on Quality of Life in Patients with Acute Leukemia Receiving Chemotherapy [ in Persian ]. Tabib Shargh. 2008;10(3):175-82.

24. Redaelli A, Stephens JM, Brandt S, Botteman MF, Pashos CL. Shortand long-term effects of acute myeloid leukemia on patient healthrelated quality of life. Cancer Treat Rev. 2004;30(1):103-17. doi: 10.1016/S0305-7372(03)00142-7. [PubMed: 14766128].

25. Chen YC, Li IC. Effectiveness of interventions using empowerment concept for patients with chronic disease: a systematic review. JBI Database of Systematic Reviews and Implementation Reports. 2009;7(27):1179-233. doi: 10.11124/01938924-200907270-00001.

26. Sadat F, Roshan N, Navi pore H,Alhani F. The effects of family-centered empowerment model on quality of life for adolescent girls with iron deficiency anemia. J Lorestan Univ Med Sci. 2014;16(4):99-88.

27. De Lorenzo F, Ballatori E, Di Costanzo F, Giacalone A, Ruggeri B, Tirelli U. Improving information to Italian cancer patients: results of a randomized study. Ann Oncol. 2004;15(5):721-5. [PubMed: 15111338].

28. Iconomou G, Viha A, Koutras A, Koukourikou I, Mega V, Makatsoris $\mathrm{T}$, et al. Impact of providing booklets about chemotherapy to newly presenting patients with cancer: a randomized controlled trial. Ann Oncol. 2006;17(3):515-20. doi: 10.1093/annonc/mdj098. [PubMed: 16344276].

29. Koenig H. Spirituality, wellness, and quality of life*1. Sexuality, Reproduction and Menopause. 2004;2(2):76-82. doi: 10.1016/j.sram.2004.04.004.

30. Lichtman MA, Williams WJ. Williams Hematol. 7 ed. New York: McGraw-Hill; 2010. 